\title{
Are Investors More Risk-Averse During Recessions?
}

\section{Hui Guo}

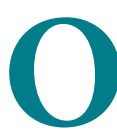

bservers of financial markets have long noted that broad stock market price indices tend to fall steeply immediately before and during recessions. In theory, a stock's price is equal to the sum of its discounted expected future dividends, and the discount rate is the expected gross stock return. Thus, it is tempting to suggest that, when the economy becomes weaker, the sharp decrease in stock prices reflects the reduction in expected future dividends. However, many studies have found that the magnitude of the cyclical fluctuation in dividends is too small to account for such large stock market price movements.

One possible explanation is that large changes in stock prices might be accompanied by swings in investors' attitude toward risk. For example, many commentators have routinely suggested that investors exhibited irrational exuberance during the dramatic stock price run-up in the late 1990s, while they were overly pessimistic during the Great Depression in the early 1930s. Campbell and Cochrane (1999) have formalized the idea in a model: When the economy goes into recession, investors have fewer resources to maintain their accustomed living standards and thus are less willing to bear financial risk. To induce them to hold stocks instead of risk-free short-term Treasury bills, for a given level of stock market risk, the expected equity premium must increase. ${ }^{1}$ Therefore, stock prices fall during recessions because dividends are discounted by a higher rate as a result of the increase in the equity premium.

Lettau and Ludvigson (2003) provide some empirical evidence for this explanation. They use expected stock market volatility, which measures the size and frequency of fluctuations in a broad stock market price index, as a gauge of stock market risk. When stock prices are expected to be more volatile, risk-averse investors will reduce their stock holdings because the chance of having a large capital loss becomes higher. Investors will hold the same amount of stocks as they did before only if they are compensated by a higher equity premium. Thus, one can use the ratio of the expected equity premium to the expected volatility-which is commonly known as the Sharpe ratio-as a measure of shareholders' risk tolerance. For example, for a given level of expected stock market volatility, investors require a higher equity premium and thus a higher Sharpe ratio if they become more risk-averse.

In the accompanying chart, we replicate Figure 3 of Lettau and Ludvigson (2003) using updated data from 1952:Q2-2004:Q4. The shaded area indicates business recessions dated by the National Bureau of Economic Research. We find that the Sharpe ratio exhibits substantial variation across time. More importantly, it increases dramatically just before and during every recession in the 52-year sample. This pattern appears to be consistent with the conjecture that investors are more risk-averse and thus demand a higher return for holding stocks during economic downturns.

Campbell, John Y. and Cochrane, John H. "By Force of Habit: A ConsumptionBased Explanation of Aggregate Stock Market Behavior." Journal of Political Economy, 1999, 107, pp. 205-51.

Lettau, Martin and Ludvigson, Sydney. "Measuring and Modeling Variation in the Risk-Return Tradeoff." Unpublished manuscript, New York University, 2003 (forthcoming in Handbook of Financial Econometrics, edited by Yacine Ait-Shalia and Lars Peter Hansen).

${ }^{1}$ The equity premium is the difference between the stock market return and the risk-free rate.

Views expressed do not necessarily reflect official positions of the Federal Reserve System. 